\title{
Toll-like receptors in COPD
}

\author{
Philip M. Hansbro ${ }^{1}$, Tatt Jhong Haw ${ }^{1}$, Malcolm R. Starkey ${ }^{1}$ and \\ Kensuke Miyake ${ }^{2}$
}

Affiliations: ${ }^{1}$ Priority Research Centre for Healthy Lungs, School of Biomedical Sciences and Pharmacy, Hunter Medical Research Institute and University of Newcastle, Callaghan, Australia. ${ }^{2}$ Division of Innate Immunity, Dept of Microbiology and Immunology, The Institute of Medical Science, The University of Tokyo, Tokyo, Japan.

Correspondence: Philip M. Hansbro, Hunter Medical Research Institute, Kookaburra Circuit, New Lambton Heights, NSW 2305, Australia. E-mail: Philip.Hansbrolnewcastle.edu.au

@ERSpublications

TLR4 and NODs could be potential therapeutic targets in chronic obstructive pulmonary disease http://ow.ly/qaqt30b7YAy

Cite this article as: Hansbro PM, Haw TJ, Starkey MR, et al. Toll-like receptors in COPD. Eur Respir J 2017; 49: 1700739 [https://doi.org/10.1183/13993003.00739-2017].

Chronic obstructive pulmonary disease (COPD) is a major cause of illness and death globally; treatments that effectively halt progression or reverse the disease, or reduce the occurrence and/or severity of exacerbations, are urgently required [1]. The lack of effective treatments results largely from the incomplete understanding of the mechanisms of pathogenesis of COPD. The pathogenesis of this disease is driven by chronic inhalation of noxious particles, often cigarette smoke, that persistently stimulates innate and inflammatory responses [2]. Over time, these responses cause repeated cycles of wound and repair that result in airway remodelling with mucus hypersecretion, collagen deposition, and fibrosis and emphysema. These combine to obstruct the airways and reduce lung function, which is characteristic of the disease.

Toll-like receptors (TLRs) play crucial roles in initiating innate immune responses upon stimulation [3]. There are 11 TLRs that occur in humans, each recognising a specific set of antigens. TLR4 responds to the ubiquitous bacterial antigen lipopolysaccharide (LPS, endotoxin) that occurs in high levels in tobacco. It induces downstream inflammatory responses through the adaptor protein myeloid differentiation primary response gene 88 (MyD88)-dependent pathway [3]. There have been surprisingly few studies of TLRs in COPD. TLR2 levels are increased in monocytes and are associated with ageing, and sputum neutrophil and matrix metalloprotease- 9 levels in COPD patients $[4,5]$. There is conflicting evidence for the roles of TLR4 whereby some studies show increases whereas other show decreased expression in patients, which is likely due to the cells, tissues or cohorts analysed [6-8]. COPD patients have increased airway colonisation by respiratory bacteria [9], and consequently it is likely that this could contribute to COPD pathogenesis through the chronic stimulation of TLR4. In this issue of the European Respiratory Journal, Di STEFANO et al. [10] examined the relationship between TLR expression, bacterial load and bronchial inflammation. They examined the expression of TLR2, -4 and -9 and the related intracellular nucleotide-binding oligomerisation domain-like receptors (NOD)-1 and -2, as well as the downstream effector molecules of these pathways, MyD88, TIRAP, pIRAK1 and 4, in the bronchial mucosa as well as the load of four common respiratory bacteria, in the bronchial mucosa of severe, stable COPD, smokers without COPD, and nonsmokers. TLR4 and, to a lesser extent, NOD1 expression was increased in COPD and correlated with elevated numbers of $\mathrm{CD} 4^{+}$and $8^{+} \mathrm{T}$-cells, airway obstruction and increased Pseudomonas aeruginosa but reduced Haemophilus influenzae load. However, surprisingly bacterial load did not correlate with increases in inflammatory cells. Thus, TLR4 and NOD1 are independently associated with inflammation

Received: April 102017 | Accepted: April 102017

Conflict of interest: None declared.

Copyright @ERS 2017 
and $P$. aeruginosa load in stable, severe COPD. It is logical that in stable COPD airway bacteria stimulate these receptors to induce cytokine and chemokine promoting inflammatory responses that control the bacteria. These responses may inhibit the growth of most bacteria including $H$. influenzae, but not prolific biofilm-forming bacteria such as $P$. aeruginosa. These changes may have a role in disease progression.

This study indicates the potential use of TLR4 inhibitors in COPD. However, further elucidation of these observations and the mechanisms involved are needed. As with any discovery, study the findings here with $\mathrm{n}=12-18$ per group should be confirmed in larger patient cohorts. The nature of the stimulation could be assessed that could be in the form of cigarette smoke components, bacterial antigens, autoantigens or damage-associated signals (DAMPs). It would also be valuable to further examine the role of oxidative stress, which is well known to be increased in COPD, and linked to TLR responses. An important question would be does oxidative stress increase responses through these receptors and/or does oxidative stress result from their stimulation in this situation, and how does bacteria load interact? Recently, NODs have been shown to be activated by bacterial infection-induced endoplasmic reticulum stress: is there a role for these processes [11]? The role of inflammasomes that promote inflammation and are associated with TLR responses, would also be topical [12]. Furthermore, with the explosion of interest in the microbiome it would be of widespread appeal to assess the relationships of changes in whole community populations with these receptors and inflammation [13]. Macrolides have recently been shown to be effective in severe asthma and have both antibacterial and anti-inflammatory responses [14]. Some benefits have also been shown in COPD [15] but their effects on TLRs and NODs have not been examined. Additionally, the use of animal models that recapitulate the hallmarks features of COPD [1, 16-18], and that utilise mice deficient in TLRs or NODs [19], or the use of antagonists would be powerful tools to dissect out the mechanisms and associations that could be validated in humans. They could also elucidate the effects of downstream effector molecules and be combined with studies using ex vivo primary human cell cultures [20], and antagonists and CRISPR technology.

This is an important study that substantially contributes to our understanding of the role of specific bacteria, TLRs and NODs in inflammation and COPD that should be of substantial interest to basic and clinical researchers and MDs interested in COPD. Its impact could be increased by other studies of the associated mechanisms and interventions.

\section{References}

1 Fricker M, Deane A, Hansbro PM. Animal models of chronic obstructive pulmonary disease. Expert Opin Drug Disc 2014; 9: 629-645.

2 Keely S, Talley NJ, Hansbro PM. Pulmonary-intestinal cross-talk in mucosal inflammatory disease. Mucosal Immunol 2012; 5: 7-18.

3 Akira S, Takeda K. Toll-like receptor signalling. Nat Rev Immunol 2004; 4: 499-511.

4 Simpson JL, McDonald VM, Baines KJ, et al. Influence of age, past smoking, and disease severity on TLR2, neutrophilic inflammation, and MMP-9 levels in COPD. Mediators Inflamm 2013; 2013: 462934.

5 Pons J, Saulleda J, Regueiro V, et al. Expression of Toll-like receptor 2 is up-regulated in monocytes from patients with chronic obstructive pulmonary disease. Respir Res 2006; 7: 64.

6 Freeman CM, Martinez FJ, Han MK, et al. Lung CD8+ T cells in COPD have increased expression of bacterial TLRs. Respir Res 2013; 14: 13.

7 Geraghty P, Dabo AJ, D'Armiento J. TLR4 protein contributes to cigarette smoke-induced matrix metalloproteinase-1 (MMP-1) expression in chronic obstructive pulmonary disease. J Biol Chem 2011; 286: 30211-30218.

8 von Scheele I, Larsson K, Dahlén B, et al. Toll-like receptor expression in smokers with and without COPD. Respir Med 2011; 105: 1222-1230.

9 Simpson JL Baines KJ, Horvat JC, et al. COPD is characterized by increased detection of Haemophilus influenzae, Streptococcus pneumoniae and a deficiency of Bacillus species. Respirology 2016; 11: e0146102.

10 Di Stefano A, Ricciardolo FLM, Caramori G, et al. Bronchial inflammation and bacterial load in stable COPD is associated with TLR4 overexpression. Eur Respir J 2017; 49: 1602006.

11 Keestra-Gounder AM, Byndloss MX, Seyffert N, et al. NOD1 and NOD2 signalling links ER stress with inflammation. Nature 2016; 532: 394-397.

12 Kim RY, Pinkerton JW, Gibson PG, et al. Inflammasomes in COPD and neutrophilic asthma. Thorax 2015; 70: 1199-1201.

13 Budden KF, Gellatly SL, Wood DL, et al. Emerging pathogenic links between microbiota and the gut-lung axis. Nat Rev Microbiol 2017; 15: 55-63.

14 Gibson PG, Yang IA, Upham JW, et al. Effect of azithromycin on asthma exacerbations and quality of life in 2 adults with persistent uncontrolled asthma (AMAZES): a randomised 3 double-blind placebo-controlled trial. Lancet 2017; in press.

15 Simpson JL Powell H, Baines KJ, et al. The effect of azithromycin in adults with stable neutrophilic COPD: a double blind randomised, placebo controlled trial. PLoS One 2014; 22: e105609.

16 Beckett EL, Stevens RL, Jarnicki AG, et al. A new short-term mouse model of chronic obstructive pulmonary disease identifies a role for mast cell tryptase in pathogenesis. J Allergy Clin Immunol 2013; 131: 752-762.

17 Hsu AC, Starkey MR, Hanish I, et al. Targeting PI3K-p110 $\alpha$ suppresses influenza virus infection in chronic obstructive pulmonary disease. Am J Respir Crit Care Med 2015; 191: 1012-1023. 
18 Hansbro PM, Hamilton MJ, Fricker M, et al. Importance of mast cell transmembrane tryptase/tryptase- $\gamma /$ prss 31 in experimental chronic obstructive pulmonary disease and colitis. J Biol Chem 2014; 289: 18214-18227.

19 Beckett EL, Phipps S, Starkey MR, et al. TLR2, but not TLR4, is required for effective host defence against Chlamydia respiratory tract infection in early life. PLoS One 2012; 7: e39460.

20 Hsu AC, Parsons K, Moheimani F, et al. Impaired antiviral stress granule and IFN- $\beta$ enhanceosome formation enhances susceptibility to influenza infection in chronic obstructive pulmonary disease epithelium. Am J Respir Cell Mol Biol 2016; 55: 117-127. 